Sloan School of Management

Massachusetts Institute of Technology (MIT)

Working Paper No. 4253-02

Harvard Law School Program on Negotiation

Harvard University

PON Working Paper

\title{
Dynamic Valuation: Preference Changes in the Context of Face-to-face Negotiation
}

\author{
Jared R. Curhan \\ MIT \\ Margaret A. Neale \\ Stanford University \\ Lee D. Ross \\ Stanford University
}

This paper can be downloaded without charge from the Social Science Research Network Electronic Paper Collection at:

http://ssrn.com/abstract_id=311527 


\section{Dynamic Valuation:}

Preference Changes in the Context of Face-to-face Negotiation

Jared R. Curhan

Massachusetts Institute of Technology

Sloan School of Management

curhan@mit.edu

Margaret A. Neale, and Lee Ross

Stanford University

\section{Forthcoming, Journal of Experimental Social Psychology. Please do not cite without permission of the authors.}

While conducting this research, the first author was supported by a National Science Foundation Graduate Research Fellowship. We thank Alex Breen, Blake Mobley, Jesse Rosencranz-Engelmann, and Eric Hamako for serving as experimenters, and we thank those who volunteered to participate in the study. We also thank Max Bazerman, Paul Berger, Rachel Croson, Rajiv Dant, Mark Lepper, Richard Moreland, Andrew Ward, and several anonymous reviewers for their helpful comments on this work. Finally, we thank Cynthia Hartley in Stanford University's Financial Aid Office for taking time to talk with us regarding financial aid negotiations. 


\begin{abstract}
This study examines the dynamics of preference change in the context of face-to-face negotiation. Participants playing the role of "student" or "financial aid officer" exchanged proposals regarding the terms of a student loan. In accord with dissonance theory, participants increased their liking for proposals they offered and/or ultimately accepted. The reactance theory prediction that participants would devalue proposals received from their counterparts was confirmed for loan officers, but not for students. A pair of experimental manipulations involving pre-rating of proposals and the opportunity for participants to engage in brief discussions prior to the initial exchange of offers mediated these effects and influenced subsequent rates of agreement as well as post-settlement satisfaction. Underlying attributional mechanisms and implications of these findings for facilitating agreements are discussed.
\end{abstract}

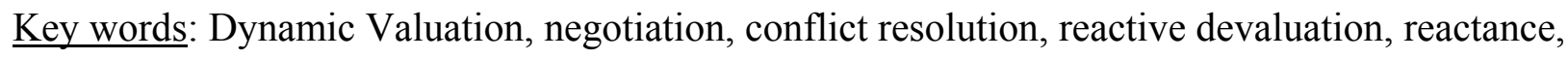
dissonance, self-perception, attribution theory, preference change. 


\section{Dynamic Valuation:}

\section{Preference Changes in the Context of Face-to-face Negotiation}

Conventional wisdom and normative theory alike suggest that people enter into negotiations with pre-existing preferences that govern both the content of the proposals they offer and the manner in which they respond to the proposals they receive. However, research on judgment and decision making over the past three decades has challenged this simple rationalist account. Decision-makers may alter or even construct their preferences as they consider available alternatives (Payne, Bettman, \& Johnson 1992; Tversky, Sattath, \& Slovic, 1988). Moreover, normatively indefensible "preference reversals" may result from changes in the way that relevant options are presented or "framed" (Grether \& Plott, 1979; Tversky \& Kahneman, 1981). Our research was designed to show that preferences of individual negotiators can be influenced by the dynamics of the negotiation process itself.

Two classic theories in social psychology_dissonance theory as proposed by Leon Festinger, and reactance theory as proposed by Jack Brehm - seem to offer predictions about the type of preference changes that can be expected to occur when negotiators exchange offers. Before proceeding to the specifics of our study, we consider these earlier theories and the predictions they offer.

Dissonance theory (Festinger, 1957; Festinger \& Aronson, 1960) proposed that individuals are motivated to reduce any psychological incongruity or discrepancy that may exist among their various cognitions, including cognitions about their own behavior and the context in which it has occurred. In particular, the theory argued that the exercise of choice among available options creates dissonance, because doing so obliges the individual to accept unattractive features of the elected option and/or to forfeit attractive features of the rejected 
option. In order to reduce such dissonance, the theory further suggested, the individual comes both to value the chosen alternative more positively than before and to value rejected alternatives less positively than before (see Aronson, 1992; Brehm \& Cohen, 1962). ${ }^{1}$ The relevance of this analysis to choices made in the context of negotiation seems clear. The decision to offer or accept a particular proposal should induce dissonance insofar as the terms of that proposal oblige the negotiator to sacrifice features that he or she would have preferred to achieve and to tolerate features that he or she would have preferred to avoid. Accordingly, the negotiator should seek to reduce dissonance by coming to feel more positively about any "package" that he or she has put on the table or has agreed upon, and thus is likely to take effect.

Reactance theory (Brehm, 1966; see also Brehm \& Brehm, 1981; Wicklund, 1974) deals not with the consequences of exercising choice, but rather the consequences of having one's choices threatened or limited. It suggests specifically that the attractiveness of options that are in danger of being lost will tend to increase, while the attractiveness of options thrust upon someone by external circumstance or by another individual will tend to decrease. The implications of this theory for preference change in the context of negotiation again seem clear. Concessions or compromise proposals put on the table by someone's counterpart in a negotiation should decline in attractiveness relative to offers not on the table - especially when the offers not on the table seem to have been deliberately "withheld."

Evidence for such a response, termed reactive devaluation, was provided in an earlier series of studies by Ross and his colleagues (see Ross 1995; Ross \& Ward, 1995, 1996; also Ma'oz, Ward, Ross, \& Katz, in press). However, none of those studies involved proposals offered and evaluated in the context of face-to-face negotiation. For example, in one study (reported in Ross, 1995) researchers surveyed attitudes of Stanford University students in the 
context of an ongoing controversy about the University's reluctance to divest itself of shares in companies that did business in South Africa (which, at that time, still practiced apartheid). Students were asked to evaluate two potential compromise proposals under consideration by the Stanford administration, one involving immediate "partial" divestment and another involving the possibility of total divestment at a later date if particular reforms were not adopted. When they were told that the administration was weighing the merits of these two proposals (along with several others), students rated the attractiveness of the two proposals about equally. However, when they were told that the administration was about to adopt one proposal rather than the other, students rated the "University's proposal" less favorably than the alternative, regardless of which proposal was purported to have been adopted.

Although these studies are provocative in their implications, none of them examined changes in people's evaluations of their own their counterpart's proposals after those proposals had been put on the table in a face-to-face negotiation. Moreover, none of these earlier studies involved manipulations of negotiation context or strategy that might affect the relevant changes in evaluation. The study reported here was designed to meet this challenge.

The joint impact of dissonance reduction and reactive devaluation can create a psychological barrier to resolving conflicts. If every offer made to resolve a conflict becomes more attractive to the party offering it, and less attractive to the party receiving it, then the "gap" to be bridged before a mutually acceptable agreement can be reached will be widened rather than narrowed by the very process of negotiation. We reasoned, accordingly, that manipulations attenuating dissonance and reactance effects should facilitate agreements. Our research tested the impact of two such manipulations - one involving the pre-rating of potential proposals, and 
another involving the introduction of a brief discussion session prior to the initial exchange of proposals.

Our study featured a structured role-play in which participants played the role of either a student seeking a loan or the financial aid officer from whom the loan was being sought. ${ }^{2}$ The ten loan packages available to the negotiators all involved some combination of loan amount, interest rate, and grace period. In each "round" of the negotiation, the participants exchanged proposals and then individually and privately evaluated the entire set of ten potential loan packages, including the one they had just proposed to their counterpart and the one their counterpart had just proposed to them. This design allowed us to determine whether participants showed the predicted enhancement in liking for the proposals they offered to their counterparts, and the predicted decrease in liking for the proposals they received from their counterparts, over the course of the negotiation.

Our first manipulation was inspired by the practice of "shuttle" diplomacy, in which mediators caucus privately with each party to assess individual priorities, and explore potential exchanges of concessions, before allowing any actual proposals to be put on the table. We thought that having participants pre-rate potential loan packages would oblige them to decide on, and make explicit to themselves (and to any observer), how favorably or unfavorably disposed they were to each package before the relevant exchange of offers. Moreover, it would oblige participants to acknowledge that any subsequent change in assessment was in fact a change. Finally, prior assessments could exert an "anchoring” effect on subsequent assessments (Tversky \& Kahneman, 1974). Thus we predicted that pre-rating would curb both the participants' tendency to devalue the particular proposal they received from their counterparts, and their tendency to value more highly the proposal they made to their counterparts. 
Our second prediction was that having participants engage in a period of discussion prior to the initial exchange of offers would curb subsequent devaluation. During that discussion, the participants would be able to exchange information about their needs and priorities, and to provide justifications for the proposals that they offered or sought. This exchange of information, we reasoned, would lead participants to make more "charitable" attributions about the content of the offers they received from their counterparts. Instead of seeing a counterpart's proposal simply as a reflection of what he or she valued, participants could attribute their counterparts' proposals to the information and justifications they had presented to their counterpart during the preceding discussion period. These more positive attributions, in turn, should reduce participants' tendency to devalue proposals received.

In summary, we predicted that offering and/or agreeing to a particular proposal would lead participants to rate that proposal more positively than they would have rated it otherwise, and that receiving a particular proposal from the other party in the negotiation would lead them to rate that proposal less positively than they would have rated it otherwise. ${ }^{3}$ We further predicted that pre-rating would curb inflation of one's own proposals, and that pre-rating and/or prior discussion preceding the exchange of offers would attenuate the devaluation of proposals from others. In other words, we predicted that the "gap" between evaluations of potential settlement proposals would be increased, and hence the likelihood of reaching agreement would be decreased, in the no pre-rate / no prior discussion condition (which conceptually was a "standard bargaining" or "control" condition), relative to any of the three other conditions. Finally, we wanted to see whether the two independent manipulations, occurring just once, before the first round of exchanges, would influence assessments of later negotiation proposals. 
Method

\section{$\underline{\text { Participants }}$}

A total of 172 undergraduates, randomly assigned to form 86 dyads participated in the study. They received no payment for their participation, although they did receive credit toward a requirement for their introductory psychology course. Data from two dyads were excluded because the participants misunderstood the experimental instructions. The remaining 168 participants (95 females, 70 males, and 3 participants whose gender was not recorded), ranging in age from 17 to 24 , comprised the 84 dyads whose data were analyzed. ${ }^{4}$

\section{$\underline{\text { Procedure }}$}

Participants were escorted into a small lab room and seated face-to-face, on opposite sides of a table. They were told that this was a study on negotiation and that they would be engaging in a role-play concerning the terms of a financial aid package. By drawing names from a hat, one participant was randomly assigned to the role of a college student and the other was assigned to the role of a financial aid loan officer. At this point, each participant received a set of printed confidential instructions consistent with his or her role in the negotiation. Both sets of instructions indicated that the negotiation involved three features or issues - the amount of a loan, the interest rate to be paid, and the grace period allowed before repayment had to begin. Participants playing the role of student were told that for them, the loan amount was of greatest importance and the interest rate of least importance, while the grace period was of intermediate importance. Participants playing the role of the loan officer were told that the loan amount was of least importance and the interest rate of greatest importance to them, with the grace period again of intermediate importance. Loan amount and interest rate thus were integrative issuesthat is, they could be "traded off" by negotiators in a manner that increased the joint value of the 
agreement for both parties (see Froman \& Cohen, 1970; Pruitt, 1983). The length of the grace period was a simple distributive issue, on which any gain to one party represented an equivalent loss to the other party.

Participants' instructions also indicated that ten agreements were available for consideration, each involving a different combination of terms with respect to the three focal issues (see Table 1). To aid in subsequent data analysis and interpretation, we applied a simple linear scoring system, reflecting the priorities that participants were instructed to follow, in order to assess the "normative" or "objective" value of each proposal to each negotiator. For example, since participants playing the role of student were told that loan amount was the most important, grace period was the second-most important, and interest rate was the third-most important, we weighted the level of a package's loan amount three times as heavily as the level of a package's interest rate when calculating normative values for those playing the student role. The resulting distribution of values for the two participants calculated in this fashion, which provided a useful covariate in subsequent analyses of the participants' assessments of the proposals they offered, received, and/or ultimately agreed upon, are shown in Table 1.

After reading their instructions, participants were told that the negotiation would be divided into separate rounds, each containing three periods: (1) an offer period in which participants exchanged written proposals; (2) a rating period in which participants privately rated all ten package deals, including of course the one they had offered and the one they had received, using 7-point Likert-type scales anchored at 1 (I hate it) and 7 (I love it); and (3) a discussion period in which participants engaged in a brief, relatively unrestrained discussion. Participants also were told that although they could say whatever they wished during the negotiation, they could not show their confidential instructions to their counterparts. 
The exchange of offers was accomplished simultaneously, by having each negotiator write his or her offer on a printed form, and then hand it to his or her partner across the negotiating table. To make it more difficult for participants to recall and simply reiterate their ratings across successive rounds, the order in which loan packages were listed on the rating form varied from round to round. During each successive discussion period, participants were allotted 2.5 minutes to argue, explain, beseech, or even deceive as they saw fit, but they were not permitted to make specific offers. This sequence of offer, rating, and discussion was repeated until either both participants put forward the same offer on the same round (thereby constituting an agreement) or until the available time was exhausted.

At the end of the experiment, the participants were debriefed. When they were asked what they thought the study was about, all of the participants mentioned "negotiation" but none guessed that the study concerned changes in valuation. In fact, when we explained our experimental hypotheses, participants for the most part doubted that their expressed preferences had changed from one round to the next as a result of the dynamics of the negotiation process. Experimental Manipulations

Four experimental conditions were created - a control condition and three treatment conditions. In the control condition, participants began their negotiations as described earlier, by exchanging initial proposals, rating all ten potential proposals, engaging in a brief period of discussion, and so forth. In the pre-rate condition, participants began by rating the desirability of each of the ten package deals using the relevant 7-point scales prior to the initial exchange of proposals. In the prior discussion condition, participants began by engaging in a brief discussion prior to the initial exchange of proposals. As in subsequent discussion periods for participants in all four conditions, these participants were free to give their counterparts information about their 
needs and priorities, justifications for certain proposals, or whatever other information they chose to provide, but were not permitted to make specific offers. In a third treatment condition, the pre-rate / prior discussion condition, participants first pre-rated the ten packages and then had a brief discussion period prior to the initial exchange of loan proposals.

Of the 84 dyads, 17 were assigned to the control condition, 18 to the pre-rate condition, 33 to the prior discussion condition, and 16 to the pre-rate / prior discussion condition. Because we were interested in the unique effects of each of our manipulations alone, as well as the effect of combining those manipulations, most of our analyses involved independent, planned, pairwise comparisons between each treatment condition and the control (no treatment) condition.

\section{Results}

Before testing our hypotheses, it is necessary to describe two analytical challenges that resulted from our research design, and to preview the analyses we employed to overcome them. Between-Condition Differences in the "Objective" Attractiveness of Proposals

Our experimental manipulations could have affected not only how participants assessed the relevant loan packages, but also which specific packages they chose to put on the table. Indeed, in the case of the prior discussion manipulation, we expected such effects to occur, because the participants would be apt to indicate which proposals they wanted to receive. To determine whether the proposals put on the table in some experimental conditions were "objectively" more valuable to the parties offering and/or receiving them than those put on the table in other experimental conditions, we conducted several analyses using the normative values in Table 1. Each analysis assessed the impact of experimental condition (specific treatment vs. control) and roles (loan officer vs. student) as independent factors. 
These analyses revealed an unanticipated but consistent main effect of roles on the objective value of proposals both to the participants who made them (all $F_{\mathrm{s}}>9.9, p \mathrm{~s}<.01$ ) and to the participants who received them (all $F_{\mathrm{S}}>4.3, p \mathrm{~s}<.05$ ). In general, proposals exchanged by participants tended to offer students more favorable terms than loan officers. These analyses also revealed the expected effect of prior discussion. That is, proposals exchanged in the two conditions involving prior discussion (prior discussion alone and prior discussion preceded by pre-rating) were normatively more valuable to their recipients than proposals exchanged in the control condition, $F(1,96)=11.0, p<.01$ and $F(1,65)=9.92, p<.01$, respectively. However, prior discussion (whether preceded by pre-rating or not) did not result in proposals that were significantly less valuable, to the person offering them, $F \mathrm{~s}<2.70, p>.10$. In other words, exchanging information about interests and priorities apparently allowed participants to better tailor proposals to their counterparts' interests without significantly compromising their own interests. In this way, they gained a "head start" in the pursuit of a mutually acceptable agreement.

In light of these between-role and between-condition differences in proposals made and received, we controlled for this factor by including our normative valuation of each proposal as a covariate in all analyses concerning initial offers made and received. Furthermore, we retained participant's role (loan officer vs. student) as an independent factor in all such analyses.

\section{Comparing Post-Exchange Assessments in Pre-Rate and No Pre-Rate Conditions}

The second analytic challenge was more straightforward. Although participants in the pre-rate condition rated the attractiveness of all ten loan packages both before and after the initial exchange of proposals, all other participants made post-exchange ratings only. Thus, although we could calculate change scores for participants in the pre-rate condition during Round 1, we 
obviously could not do so for participants in the no pre-rate condition. As a result, we could not directly compare the amount of enhancement or devaluation of initial offers that occurred in the pre-rate versus no pre-rate conditions. To overcome this challenge, we simply focused our analyses on post-exchange assessments of proposals, using the normative values of proposals as a covariate.

$\underline{\text { Negotiation Outcomes }}$

Before examining participants' evaluations of the proposals they offered and received in the various conditions of the experiment, it is worth noting the final negotiation outcomes achieved in those conditions. Of the 84 dyads, 7 dyads reached agreement in the first round and therefore did not proceed to the second round. Five of these dyads were in the prior discussion condition and two were in the pre-rate / prior discussion condition. Thirty-eight dyads completed only two rounds. Seventeen of these dyads reached agreement on that second round, and 21 failed to reach agreement, but used all of the available time. Of the remainder, 35 dyads completed three rounds (21 reached agreement and 14 used all of the available time) and 4 dyads completed four rounds ( 3 reached agreement and one used all of the available time).

In the following analyses, we considered only the between-condition differences in agreement reached by the end of Round 2, because after that point the effects of the Round 1 manipulations on agreement were confounded with their effects on the number of rounds that participants had time to complete. As Figure 1 shows, the percentage of dyads reaching agreement by the end of Round 2 was lowest for the control condition. Following a statistical procedure described by Langer and Abelson (1972) for comparing proportions in four-fold tables, we performed an arcsine transformation on the proportions of participants reaching agreement in each condition, and then subjected the transformed data to a single statistical 
contrast comparing the control condition with the three treatment conditions. The results of this contrast confirmed our prediction. Dyads initially assigned to the control condition reached a significantly lower proportion of agreements than did dyads assigned to our three treatment conditions (pre-rating alone, prior discussion alone, or a combination of pre-rating and prior discussion), $F(1,8)=4.32, p<.04$.

\section{Evaluations of Initial Proposal Offered}

We hypothesized that offering proposals to their counterparts would lead participants to rate such proposals more positively than they would have rated them otherwise, but that prerating proposals would curb this tendency. Figure 2 shows the mean pre-exchange and postexchange ratings of the initial proposals offered by control condition and pre-rate condition participants. In the case of control condition participants, the mean pre-rating reflects the mean ratings of proposals made by the participants in the two pre-rate conditions who later went on to offer those proposals themselves.

We first tested the enhancement effect among control condition participants by subjecting their post-Round 1 ratings and "imputed" pre-ratings to a paired-sample t-test. We found, as predicted, that the act of offering a proposal seemed to enhance its attractiveness to the party who offered it, $M_{\text {pre }}=5.43, M_{\text {post }}=6.48, t(32)=3.94, p<.001$. This enhancement was apparent both in loan officers' assessments of the proposals that they made to students, $t(15)=2.72$, $p<.05$, and in students' assessments of the proposals that they made to loan officers, $t(16)=6.12, p<.001$. Assessments of proposals neither made nor received showed no enhancement, $M_{\text {pre }}=3.90, M_{\text {post }}=3.80, t<1$.

We then compared the magnitude of this enhancement effect for control condition participants to that shown by participants in the two experimental conditions where pre-ratings 
were made. Specifically, we performed a pair of two-way analyses of covariance on post-exchange ratings of participants' initial offers, in each case treating experimental condition (control vs. treatment) and role (loan officer vs. student) as independent factors, with normative values of the relevant offers to the participants offering them as a covariate. The role effect was not significant either as a main effect or as an interaction in any of these analyses, all $p \mathrm{~s}>.10$. As predicted, the ANCOVA contrasting the pre-rating alone condition with the control condition yielded a significant main effect of condition, $F(1,69)=4.28, p<.05$. However, there was no significant main effect of condition in the ANCOVA contrasting the pre-rate/prior discussion condition with the control condition, $F(1,96)=2.34, p=.13 .^{5}$

Evaluations of Initial Proposal Received

We hypothesized that receiving proposals from their counterparts would lead participants to rate such proposals less positively than they would have rated them otherwise. We also predicted that pre-rating and/or prior discussion would attenuate this devaluation phenomenon. Figure 3 shows participants' mean pre-exchange and post-exchange ratings of the initial proposals received by participants in the control condition versus those in the other three treatment conditions. In the case of participants in the control and prior discussion only conditions, these pre-ratings were the mean ratings of the relevant proposals by all participants in the two conditions where pre-ratings were made.

Figure 3 shows the results separately for "students" and "loan officers" because this role assignment variable produced a significant main effect on the magnitude and direction of change shown by participants. Loan officers generally devalued the proposals that they received from students, as we predicted, but students generally enhanced their assessments of the proposals that 
they received from loan officers. In other words, our reactive devaluation hypothesis was confirmed for loan officers, but not for students.

Notwithstanding this unanticipated effect of role, it was still possible to compare changes in valuation among control condition participants to changes in valuation among participants in each of the other three treatment conditions. We performed a series of two-way analyses of covariance on post-exchange ratings of initial offers received with experimental condition (control vs. treatment) and role (loan officer vs. student) as independent factors, and with the normative values of offers received as a covariate. As predicted, the ANCOVA contrasting the control condition with the pre-rate condition and the ANCOVA contrasting the control condition with the prior discussion condition yielded significant main effects of condition, $F(1,69)=8.14$, $p<.01$ and $F(1,96)=6.99, p=.01$, respectively. Somewhat surprisingly, the ANCOVA contrasting the control condition with the condition combining pre-rating and prior discussion condition yielded only a marginally significant effect of condition, $F(1,65)=3.20, p<.10$.

It is worth noting that participant's role was not significant either as a main effect or as an interaction in any of these analyses (all $p s>.05$ ), once we controlled for the difference in the objective attractiveness of the offers received by these two types of participants. That is, both types of participants showed less positive responses to their counterparts' proposals in the control condition than in the three experimental conditions. But in the case of "students," this difference was reflected in smaller enhancement effects rather than larger devaluation effects. The "Gap" to be Bridged Between Participants

An intuitive measure of how our three manipulations affected the difficulty of reaching agreement is the gap between participants' assessments of the loan packages they proposed in Round 1 to their counterparts and their assessments of the loan packages that their counterparts 
proposed to them (see Figure 4). We compared the size of this gap among control condition participants to the size of the gap in each of the other three treatment conditions, once again using a series of two-way analyses of covariance on the relevant discrepancy measures with experimental condition and role as independent factors. In these analyses, however, it was the gap between the normative values of the offered and received loan packages that served as the covariate.

The ANCOVA contrasting the control condition with the pre-rate condition, the ANCOVA contrasting the control condition with the prior discussion condition, and the ANCOVA contrasting the control condition with the pre-rate / prior discussion condition, all yielded significant main effects of condition, $F(1,68)=9.91, p<.01 ; F(1,92)=6.93, p=.01$; and $F(1,64)=5.46, p<.05$, respectively. Once again, no main effects or interactions involving roles were significant, all $p \mathrm{~s}>.05$. Even after controlling for the actual gaps that had to be bridged in each condition, our manipulations thus left participants with a smaller subjective or psychological gap to be bridged as they entered Round 2. It was this reduction in initial "gap," we believe, that explains the higher rates of agreement in the three experimental conditions than in the control condition by the end of that round.

Changes in Evaluations During Later Rounds

Although our primary focus was the changes in evaluations that occurred as a result of the manipulations in Round 1, we did examine changes that occurred in later rounds of the negotiation as well. Because we found no evidence of devaluation in the initial proposals received in either of the two conditions involving prior discussion, and participants in all conditions engaged in a discussion period in each subsequent round, we expected to find little evidence of reactive devaluation in later rounds. And no such devaluation occurred. However, 
there was still clear evidence of enhancement of own proposals in those later rounds.

Paired-sample $t$-tests revealed a significant increase in evaluations of proposals made during Round 2 (compared to evaluations of those same proposals in Round 1) $M_{\text {pre }}=4.93$, $M_{\text {post }}=5.58, t(148)=6.17, p<.001$. There was also a small but significant between-round decrease in evaluations of proposals neither made nor received, $M_{\text {pre }}=3.98, M_{\text {post }}=3.88$, $t(33)=2.09, p<.05$. Similar $t$-tests on the data from Round 3 again revealed an increase in evaluations of the proposals made, $M_{\text {pre }}=5.00, M_{\text {post }}=5.47, t(74)=3.73, p<.001$, but no change in evaluations of the proposals neither made nor received, $M_{\mathrm{pre}}=4.01, M_{\mathrm{post}}=4.01$, $t(71)=0.03, p=$ n.s. In other words, participants increasingly liked the proposals they were offering (and/or increasingly offered the proposals that they liked) as the negotiations progressed.

\section{$\underline{\text { Evaluations of Agreed-Upon Loan Packages }}$}

We hypothesized that agreeing on a loan package, and thus accepting its terms, would lead participants to rate that package more positively — in service of dissonance reduction — than they would have rated it otherwise. We examined such changes in evaluations for dyads that reached agreement both in Round 1 and in Round 2. The paired-sample t-tests we performed revealed that the seven dyads who reached agreement in Round 1 had much greater liking for agreed-upon loan packages, $M_{\text {pre }}=3.86, M_{\text {post }}=6.00, t(13)=6.17, p<.001$, while no significant changes in liking were apparent for the other nine loan packages, $M_{\text {pre }}=3.87$, $M_{\text {post }}=3.64, t(13)=1.15, p=.27$. Analyses of Round 2 valuations revealed that the 17 dyads who reached agreement also had greater liking for the agreed-upon loan packages, $M_{\text {pre }}=4.56$, $M_{\text {post }}=5.65, t(33)=4.06, p<.001$, but no significant changes in liking for the other nine loan 
packages, $M_{\text {pre }}=4.03, M_{\text {post }}=3.93, t(33)=0.99, p=.33$. The increase in liking for agreed-upon proposals was significantly greater than the increase in liking for proposals that were offered, but not agreed upon, in Round 1, $t(162)=3.02, p<.01$, and in Round 2, $t(147)=2.35, p<.05$.

\section{Discussion}

Our study provided evidence for both dissonance reduction and reactance in participants' assessments of the proposals they exchanged in the dynamic process of face-to-face negotiation. Dissonance reduction was seen in the tendency for participants to increase their liking for the proposals that they offered. Dissonance reduction was also seen in the tendency for participants to assess proposals that were agreed upon, and would therefore "take effect," more positively than proposals that they proposed, but were not accepted by their counterparts.

Reactance was seen in the overall tendency for loan officers to devalue the proposals that they received from students. However, we did not see any tendency for students to devalue the proposals that they received from loan officers. It is tempting to dismiss the latter result by suggesting that students did not devalue the proposals they received because those proposals were relatively attractive to them - in contrast to loan officers, who received proposals that were both objectively and subjectively less attractive to them. Although this difference in proposal attractiveness may have played some role in our results, we don't believe that it provides a completely satisfactory explanation. First, we know that in some of the studies cited earlier, proposals were "reactively" devalued in spite of being attractive to the recipients who devalued them. More importantly, we found no evidence in our study that loan officers' devaluation of the proposals that they received was any weaker for attractive rather than unattractive proposals, 
regardless of whether we used the "objective" judges' assessments of proposals or the preratings made by our participants as the measure of attractiveness in the relevant analyses.

Other possible explanations for this asymmetry in responses might involve differences in the relative power attached to the two roles, or the congruency between these roles and the participants' actual status as undergraduates (and potential loan-seekers). At this point, however, we see no support for such conjectures in the results from other role-play studies conducted in our lab (e.g., Lepper, Ross, Ward, \& Tsai, 1997), and so we must leave this question open for future research. Nevertheless, the failure to find reactive devaluation among participants playing one role in our study, especially given the between-condition differences that we found, allows us to rebut any claim that reactive devaluation is "obvious," normatively demanded, or the inevitable result of some procedural artifact.

Beyond documenting dissonance and reactance effects in the dynamic process of negotiation, our study explored the impact of two manipulations. Pre-rating, we discovered, inhibited changes in assessment (whether positive or negative in direction), whereas prior discussion enhanced assessments of proposals received. In the case of loan officers, prior discussion led to a decrease in reactive devaluation of the loan packages that were proposed by the students. In the case of students, prior discussion led to increases in evaluations of the loan packages presented to them by the loan officers. The absence of both pre-rating and prior discussion before the first exchange of proposals (the standard or control condition that exists when parties begin a negotiation by simply making proposals to one another) seemed to pose a particular obstacle to successful negotiation, in terms of the gaps between the participants' evaluations of proposals made during the first round, and in terms of the likelihood that early agreement would be reached. 
A methodological note is in order here. By including in our analyses dyads that reached agreement, we effectively increased the relevant enhancement effects in evaluations of the proposals that were offered (because agreement increased the participants' motivation to find such proposals attractive), but decreased any reactive devaluation of the proposals that were received (because agreed-upon proposals were, by definition, those that participants proposed as well as received). It would have made little sense to exclude these proposals from our analyses, however, especially given our interest in the effects of prior discussion. The period of discussion prior to the initial exchange of offers was designed to reduce reactance on the part of recipients and thus to foster agreement. Eliminating dyads that reached agreement would have eliminated precisely those dyads that most showed the predicted attenuation of the reactive devaluation effect.

Although our results were provocative, the design of the study did create some problems of interpretation. One set of problems, which we attempted to address by using an appropriate covariate, arose from the fact that our manipulations were bound to produce differences in the content (and hence the attractiveness) of the proposals that were offered in the different experimental conditions. The fact that participants were negotiating in accordance with priorities assigned by the experimenter, rather than their own preferences and values, also may have created some difficulties. Even telling participants that this was a study on negotiation could have caused them to use their discussion periods to seek an agreement, rather than settling for a stalemate.

Another set of problems arose from the fact that participants were free to do as they chose during the discussion period preceding the initial exchange of offers, leaving us with no satisfactory way to determine which features or consequences of that discussion were helpful 
during the subsequent search for agreement. This latter set of problems, which involves the important issue of determining mediational processes, was exacerbated by the fact that we did not try to measure the participants' reactions to each other's proposals, to each other, or to the negotiation process itself. Finally, we must acknowledge that the apparently beneficial effects of prior discussion on rates of settlement might have occurred simply because such discussion gave the participants more time to work at the task of negotiation and thus more opportunity to reap its benefits.

Why might prior discussion facilitate agreement? One factor, of course, is the opportunity for participants to exchange information about their needs, preferences, and priorities that in turn allowed them to choose offers that would be more acceptable to their counterparts. Another factor is the feeling that one's "voice" has been heard and acknowledged (Lind \& Tyler, 1988). In the absence of prior discussion, it is not unreasonable to assume that an initial offer from one's counterpart would be "unbalanced" in the relative weight given to the interests of the party offering the proposal versus the interests of the party receiving it. As such, it seems reasonable for the recipient to discount (or devalue) such an offer.

In this regard, we should mention the results of dissertation research conducted in our laboratory by Andrew Ward. In his research (Ward, 1997), students negotiated with a confederate of the experimenter who first expressed disagreement about the advisability of enacting new drug laws, and then offered a compromise proposal. What varied, and what seemed to influence the students' responses, was the presence or absence of acknowledgement. When the confederate claimed that his proposal was formulated prior to hearing the student plead his or her case, the response from the student tended to be negative and agreements were infrequent. When the same proposal was offered, but the adversary dramatically cast aside one that he claimed to 
have formulated beforehand, and then offered "instead" one that he claimed to be new and responsive to the student's arguments, the result was more positive; the confederate's proposal was judged to be a larger concession and agreement was more frequent. Earlier work by Benton, Kelley and Liebling (1972), showing the value that negotiators place on control over the process and outcome of negotiation, is relevant to this point as well.

Clearly, practitioners and theoreticians alike would welcome research that utilizes a combination of experimental manipulation and correlational analysis to explore the extent to which (and the processes by which) discussion and/or pre-rating of proposals prior to their exchange can facilitate the search for agreement. We invite our colleagues to take up the challenge of investigating what types of discussion content and context, and which pre-negotiation strategies and tactics, serve both partisan objectives and the shared objective of resolving conflict as well as achieving high quality, value-creating settlements. We also believe that more research should focus on dynamic, face-to-face negotiation in which partisans deal with issues of concern to them - even if such negotiation is "hypothetical" in nature, because any agreements reached will not be enacted. Our study illustrates some of the methodological challenges that can arise when participants are allowed to bargain in this way. We hope that it also shows that the rewards of doing such research are commensurate with the difficulties. 


\section{References}

Aronson, E. (1992). The return of the repressed: Dissonance theory makes a comeback. Psychological Inquiry, 3, 303-311.

Bem, D. J. (1967). Self-perception: An alternative interpretation of cognitive dissonance phenomena. Psychological Review, 74, 183-200.

Bem, D. J. (1972). Self-perceptions theory. In L. Berkowitz (Ed.), Advances in experimental social psychology (Vol. 6, pp. 1-62). New York: Academic Press.

Benton, A. A., Kelley, H. H., \& Liebling, B. (1972). Effects of extremity of offers and concession rate on the outcomes of bargaining. Journal of Personality and Social Psychology, 24, $73-83$.

Brehm, J. W. (1966). A theory of psychological reactance. New York: Academic Press.

Brehm, S. \& Brehm, J. W. (1981). Psychological reactance: A theory of freedom and control. New York: Academic Press.

Brehm, J. W. \& Cohen, A. R. (1962). Explorations in cognitive dissonance. New York: Wiley.

Festinger, L. (1957). A theory of cognitive dissonance. Stanford, CA: Stanford University Press.

Festinger, L. \& Aronson, E. (1960). The arousal and reduction of dissonance in social contexts. In D. Cartwright \& A. Zander (Eds.), Group dynamics (pp. 214-231). Evanston, IL: Row, Peterson.

Froman, L. A. \& Cohen, M. D. (1970). Compromise and logroll: Comparing the efficiency of two bargaining processes, Behavioral Science, 30, 180-183. 
Grether, D. M. \& Plott, C. R. (1979). Economic theory of choice and the preference reversal phenomenon. The American Economic Review, 69, 623-638.

Langer, E., J. \& Abelson, R. P. (1972). The semantics of asking a favor: How to succeed in getting help without really dying. Journal of Personality \& Social Psychology, 24, 26-32.

Lepper, M. R., Ross, L., Ward, A., Tsai, J. (1997). Reactive devaluation: Exploration of a robust phenomenon. Unpublished Manuscript, Stanford University, Stanford, CA.

Lind, E. A. \& Tyler, T. (1988). The social psychology of procedural justice. New York: Plenum Press.

Ma'oz, I., Ward, A., Katz, M., \& Ross, L. (in press). Reactive devaluation of an "Israeli" vs. "Palestinian" peace proposal. Journal of Conflict Resolution.

Payne, J. W., Bettman, J. R., \& Johnson, E. J. (1992). Behavioral decision research: A constructive processing perspective. Annual Review of Psychology, 43, 87-131.

Pruitt, D. G. (1983). Achieving integrative agreements. In M. H. Bazerman \& R. J. Lewicki (Eds.), Negotiating in organizations (pp. 35-49). Beverly Hills: Sage Publications.

Ross, L. (1995). Reactive devaluation in negotiation and conflict resolution. In K. Arrow, R. H. Mnookin, L. Ross, A. Tversky \& R. Wilson (Eds.), Barriers to conflict resolution (pp. 2642). New York: W. W. Norton.

Ross, L. \& Ward, A. (1995). Psychological barriers to dispute resolution. In M. Zanna (Ed.), Advances in experimental social psychology (Vol. 27, pp. 255-304). San Diego: Academic Press.

Ross, L. \& Ward, A. (1996). Naive realism in everyday life: Implications for social conflict and misunderstanding. In E. S. Reed, E. Turiel, \& T Brown (Eds.), Values and knowledge (pp. 103-135). Mahwah, NJ: Lawrence Erlbaum. 
Tversky, A., \& Kahneman, D. (1974). Judgment under uncertainty: Heuristics and biases. $\underline{\text { Science, } 185}, 1124-1131$.

Tversky, A. \& Kahneman, D. (1981). The framing of decisions and the psychology of choice. Science, 21, 453-458.

Tversky, A., Sattath, S., \& Slovic, P. (1988). Contingent weighting in judgment and choice. Psychological Review, 95, 371-384.

Ward, A. (1997). Overcoming barriers to the negotiated resolution of disputes. Unpublished doctoral dissertation, Stanford University, Stanford, CA.

Wicklund, R. A. (1974). Freedom and reactance. Potomac, MD: Erlbaum. 


\section{Footnotes}

${ }^{1}$ Self-perception theory, which was proposed as an alternative explanation for dissonance phenomena (Bem, 1967, 1972), offered a less motivational account of these changes. Selfperception theory suggested that when actors are asked to reflect on their choices after the fact, they treat their selections among alternatives as evidence about their private preferences — much as they would in making inferences about the preferences of a stranger whom they observed making the same selections under the same circumstances. Accordingly, they infer that they must have liked the option they chose, and not the options they rejected

${ }^{2}$ We designed a negotiation role-play concerning the issue of financial aid only after consulting with financial aid officers, who informed us that negotiations between financial aid officers and students are indeed quite common.

${ }^{3}$ When a proposal made by Party A is accepted by Party B, Party A may like the proposal more as a function of having generated it and as a function of knowing that it will soon take effect (consistent with dissonance theory), but may like the proposal less as a function of its having been accepted by his or her counterpart (consistent with reactance theory). In the context of our experiment, we predicted that, on balance, both participants would like their final agreements more as a function of having generated them (i.e. that dissonance reduction would be more relevant than reactive devaluation).

${ }^{4}$ No attempt was made to control the gender composition of these dyads. Subsequent analyses of how the participants evaluated offers made and offers received revealed no main effects of participants' gender or the gender composition of dyads, and no interactions between these variables and our two independent variables. Accordingly, gender receives no further consideration in this report. 
${ }^{5}$ Although we had no particular expectation about the interaction between the pre-rating and prior discussion manipulations, we were surprised that these variables in combination were somewhat less effective at reducing the enhancement effect than pre-rating alone. Perhaps prior discussion increased participants' feelings of commitment or ownership of the proposals they made. 
Table 1

Ten Permissible Loan Packages, and "Normative" Assessments of their Value to the Participants

Three Issues Being Negotiated "Normative” Value to Participants

$\begin{array}{lllllll}\text { Package } & \text { Amount of } & \text { Interest } & \text { Grace } & & \text { Value to } & \text { Value to } \\ \text { Deal } & \text { Loan } & \text { Rate } & \text { Period } & \text { Officer } & \text { Student }\end{array}$

\begin{tabular}{llllll}
\hline A & $\$ 2,500$ & $3 \%$ & 6 months & 3.24 & 3.24 \\
B & $\$ 2,500$ & $5 \%$ & 9 months & 3.54 & 3.54 \\
C & $\$ 4,000$ & $5 \%$ & 3 months & 4.44 & 3.24 \\
D & $\$ 4,000$ & $5 \%$ & 6 months & 3.84 & 3.84 \\
E & $\$ 4,000$ & $8 \%$ & 3 months & 5.34 & 2.94 \\
F & $\$ 4,000$ & $8 \%$ & 9 months & 4.14 & 4.14 \\
G & $\$ 8,000$ & $3 \%$ & 3 months & 3.24 & 4.44 \\
H & $\$ 8,000$ & $5 \%$ & 9 months & 2.94 & 5.34 \\
I & $\$ 8,000$ & $8 \%$ & 3 months & 5.04 & 3.84 \\
J & $\$ 8,000$ & $8 \%$ & 9 months & 3.84 & 5.04 \\
\hline
\end{tabular}

Note. "Normative" values of each package deal were calculated separately for each role, reflecting both the rank of each option (e.g., $\$ 2,500$ highest, $\$ 4,000$ intermediate, and $\$ 8,000$ lowest for the loan officer, and vice versa for the student) and the priority assigned to each issue (e.g., interest rate highest, grace period intermediate, and loan amount lowest for the loan office, and vice versa for the student). The relevant weighted values then were "normalized" so that their overall mean and standard deviation would be comparable to those of the participants' own subjective ratings. 


\section{Figure Captions}

Figure 1. Percentage of participants reaching agreement by the end of Round 2. Absolute number of dyads reaching agreement and total number of dyads in each condition are presented in parentheses.

Figure 2. Participants' ratings of their own initial proposal. For participants in the control condition, the mean pre-rating reflects the pre-ratings of proposals made by participants in the two pre-rate conditions who later went on to offer those particular proposals.

Figure 3. Participants' ratings of initially received proposals. For participants in the control and prior discussion only conditions, the mean pre-rating reflects ratings of the relevant proposals, made by all participants in the two conditions where pre-rating took place.

Figure 4. Mean "gap" between participants' ratings of proposals made and received in Round 1. 
Dynamic Valuation 31

Figure 1

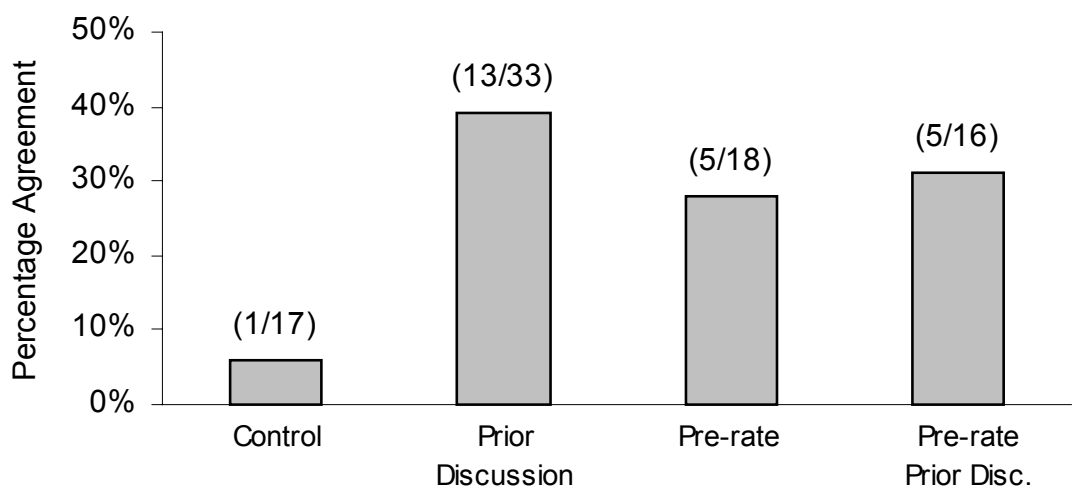

Experimental Condition 
Figure 2

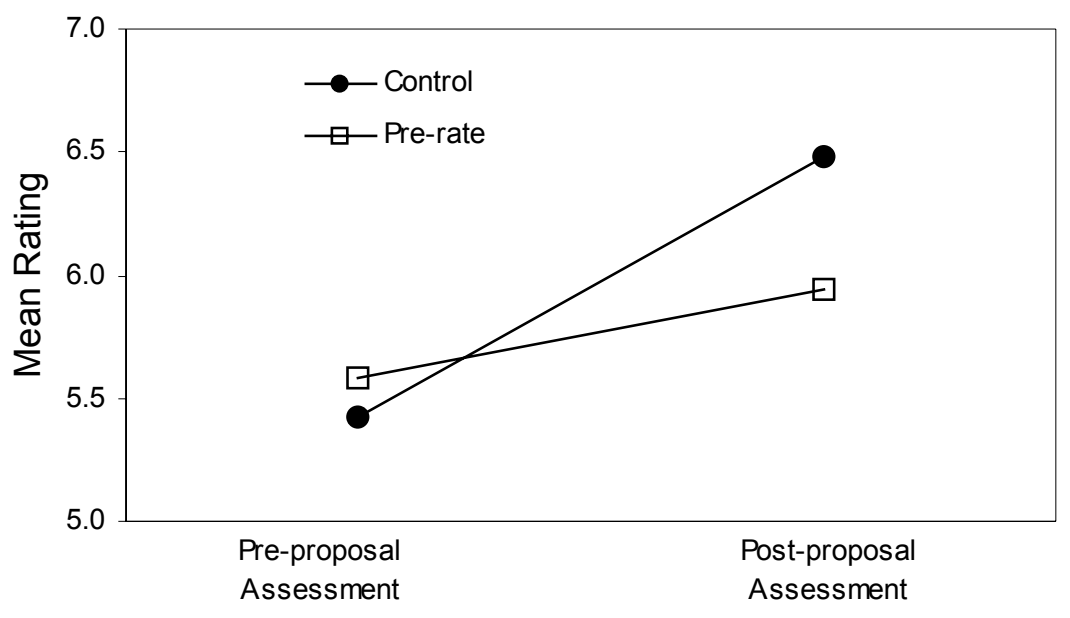




\section{Figure 3}

(a) Loan Officers and Students Combined

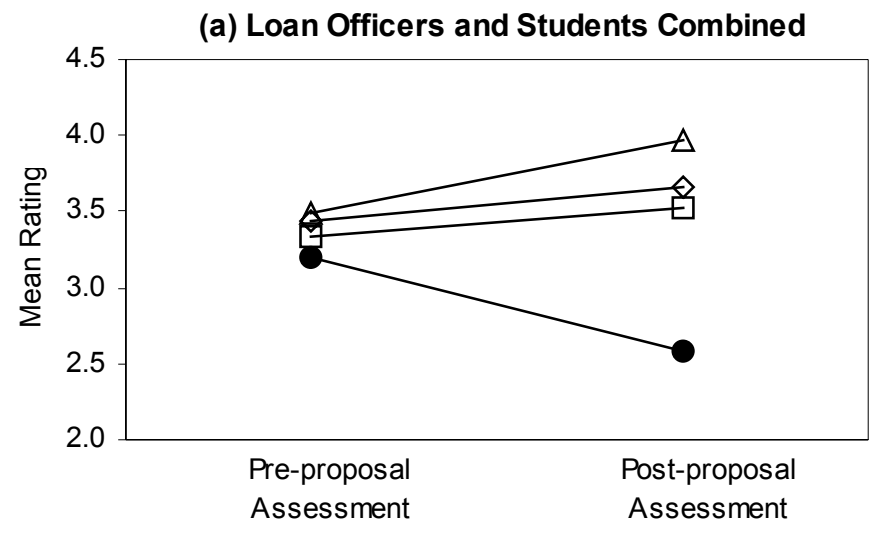

(b) Loan Officers Only

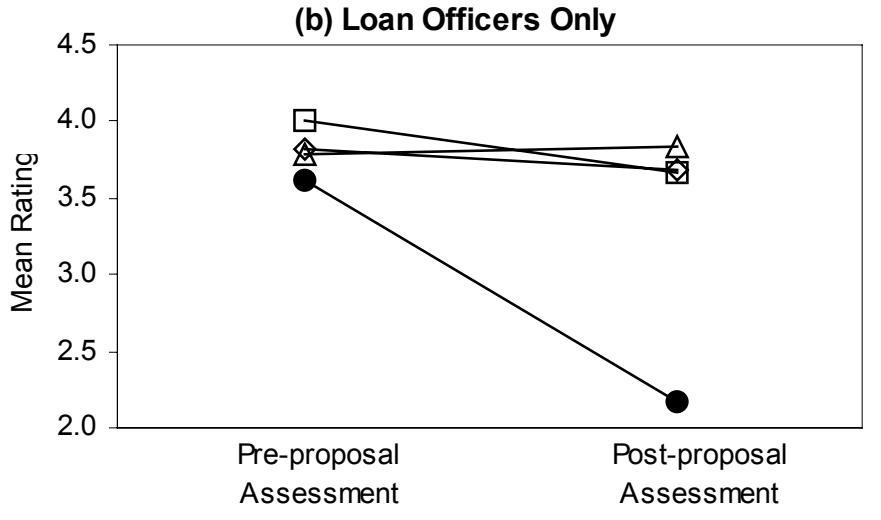

(c) Students Only

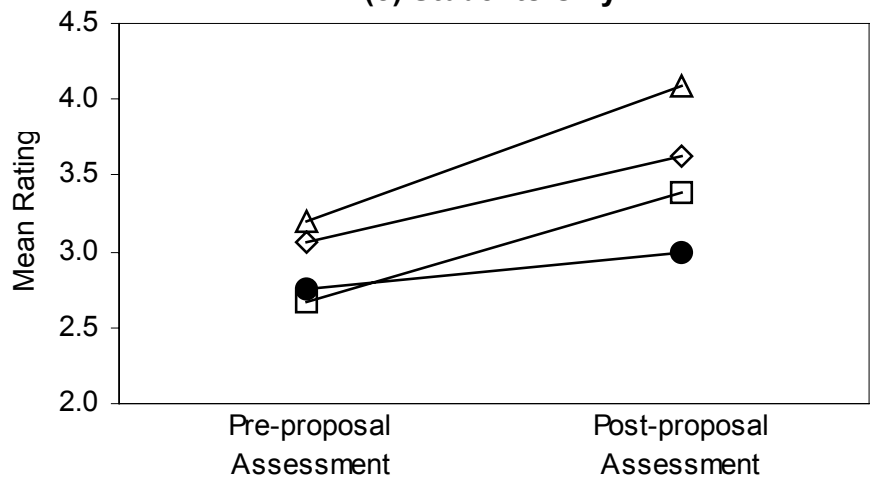

$\begin{array}{|ll|}\square-\text { Control } & \triangle \text { Prior Discussion } \\ \square-\text { Pre-rate } & \checkmark \text { Pre-rate / Prior Discussion }\end{array}$


Dynamic Valuation 34

Figure 4

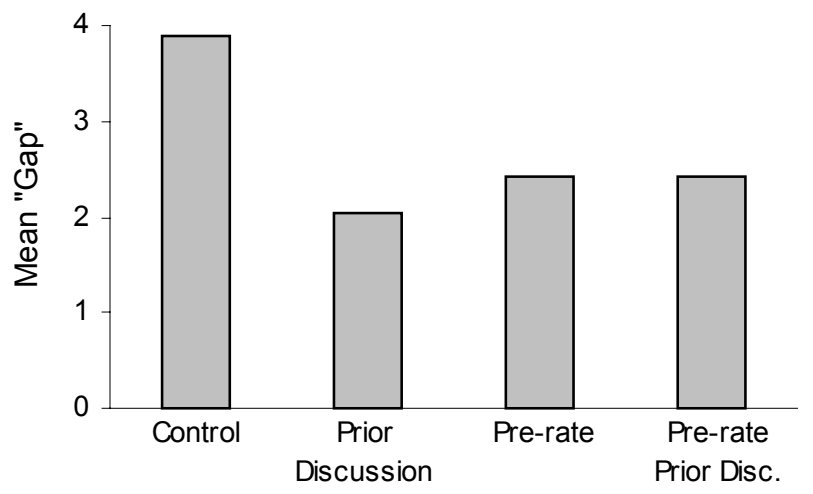

